\title{
The Experimental Approach to Studying Employers' Hiring Behavior
}

\author{
KLARITA GËRXHANI
}

\begin{abstract}
This essay advocates the use of experimental methods to study labor demand. Experimentation contributes to a better understanding of employers' hiring behavior by establishing what is cause and what is effect in observed behavior and allows for a better grip on the mechanisms underlying the hiring process. Given the difficulties in obtaining information from employers, experiments offer a fruitful alternative route to collecting information about the hiring process. The limited existing research provides a basis for new and promising steps into the future. To address research questions related to employers' hiring behavior, I propose combining experimental methods; implementing cross-country experimental designs; conducting experiments on online labor markets; and using experimental control to explore the interaction between social context and biological factors. Setting these steps will give employers' decisions the attention they deserve when it comes to the important role that hiring plays in generating labor market (in)equalities.
\end{abstract}

\section{INTRODUCTION}

A typical employment relationship consists of an exchange of labor for money. The process of establishing such a relationship thus involves both an employee seeking to offer his or her labor and an employer offering a position. The first aspect, job seeking, has received abundant scholarly attention (Granovetter, 1974). Although the latter aspect is a necessary condition for a job match to take place-without an available job, a job search cannot succeed-employers' hiring behavior and strategies remained under-researched for many decades. Fortunately, this has started to change.

Bills, Di Stasio, and Gërxhani (2017) provide a recent and extensive overview of the literature focusing on the demand side of the hiring process. Studies have by and large been based on observational field and survey data, but recently a few studies have started to appear that

Emerging Trends in the Social and Behavioral Sciences.

Robert Scott and Marlis Buchmann (General Editors) with Stephen Kosslyn (Consulting Editor).

(C) 2017 John Wiley \& Sons, Inc. ISBN 978-1-118-90077-2. 
use (quasi)experimental data. While observational and survey data can provide rich detail on how employers perceive the information they receive about potential employees, such data cannot address issues of endogeneity and self-selection bias, and cannot establish what is cause and what is effect (Mouw, 2003). Moreover, observing employers' behavior is quite difficult in and of itself. Lack of data has been an important hurdle to studying employers' hiring behavior in much of social science research. Compared to employees, employers are more resistant to information sharing because of time constraints, reluctance to public exposure, or lack of obvious benefits from collaboration. Although progress has been made, more effort and creativity are needed to open the black box of employers' decision-making.

This essay advocates the use of experimental methods to better understand employers' behavior. Over the past 20 years, there has been a noticeable increase in the use of experiments by social scientists to study a rich platter of phenomena (Jackson \& Cox, 2013). The method's main strength is the control it provides. Causal knowledge requires controlled variation and the laboratory allows for tight control over the environment in which an interaction takes place (Falk \& Heckman, 2009). "The experimental method is extremely powerful, particularly in largely eliminating the contaminating role of unobserved confounders and thereby making causal explanation more secure..." (Jackson \& Cox, 2013, p. 43). Moreover, the experimental method allows one to isolate the mechanisms underlying employers' hiring behavior, which is hard to achieve based on observational data. Finally, depending on the type of experiment conducted-see below-experimentation provides a relatively low-cost tool (compared to observational studies) to better understand employers' hiring behavior. As Bills et al. (2017) argue, this understanding is important because employers play a major role in determining opportunities and (in)equalities in the labor market.

\section{THE EXPERIMENTAL METHOD}

A major goal of empirical research is to find relations between variables. This is often done using naturally occurring data, survey data, or in-depth interviews. With such data, the challenge is to establish whether a relation between variables is causal or merely a correlation. One can attempt to address the causality issue by applying proper statistical or econometric techniques. Alternatively, one can generate new data with experimental control in a laboratory or in the field. The experimental method in the social sciences collects data on social phenomena in a controlled-laboratory or field-environment. Like theory and empirics, experiments are used to 
explain social activities. The experimental method enables one to measure key explanatory factors such as beliefs and social norms and to relate these to observed behavior. This behavior is studied while controlling for (i.e., holding constant), "institutions," such as labor market rules. In addition, experiments allow for either control or measurement of micro-level mechanisms. For example, one can measure subjects' emotions directly (physiologically or via a questionnaire) or induce power relations in the experimental rules.

Depending on the degree to which a researcher exercises control over the environment of interest, experiments can be categorized as (i) laboratory experiments; (ii) "artefactual" and "framed" field experiments (Harrison \& List, 2004); and (iii) "natural" field experiments. ${ }^{1}$

In a laboratory experiment, human volunteers make decisions in a framework designed by the experimenter. Participants are given instructions about available actions and how their decisions, possibly in interaction with others' decisions, determine their monetary payoffs. In most experiments these payoffs are paid out. They are used to incentivize serious engagement and to create real (as opposed to hypothetical) consequences of the actions taken. $^{2}$ Laboratory experiments are thought to score highly on internal validity because of the highest possible experimental control they offer.

A disadvantage of laboratory experiments is a possibly limited external validity due to an artificial, "unnatural" setting. Participants' behavior may not be representative for the population at large and the experimental task may be abstract, relative to situations people face in daily life. The severity of this limitation depends closely on the research question one is addressing (Schram, 2005). Field experiments offer an alternative with (in many cases) higher external validity. Artefactual and framed field experiments are methodologically closest to a laboratory experiment. An artefactual field experiment is run in a laboratory, but with a non-standard subject pool (e.g., firm managers). Framed field experiments involve running a controlled experiment in the participants' natural environment, for example, on the premises of an organization (lab-in-the-field). However, the fact that participants in framed field experiments typically know each other and may share experiences and views that are unknown to the experimenter reduces control and may therefore diminish internal validity compared to the laboratory environment.

Natural field experiments are also conducted in the participant's own environment, but here a natural context is added. Instructions and tasks are framed in a way that fits the organization to which the participants

\footnotetext{
1. For excellent methodological overviews, see Falk and Heckman (2009), and Jackson and Cox (2013).

2. Across the social sciences, there are differences in how instructions are applied and in the incentives used. For a thorough discussion, see Hertwig and Ortmann (2001).
} 
belong (e.g., related to a workplace decision of hiring a candidate). Typically, participants are unaware that they are participating in an experiment (Przepiorka \& Diekmann, 2013). For example, participants may be members of an organization doing their usual tasks, while the circumstances have been structured in a way determined by the experimenter. Making decisions in a setting that is completely natural to participants yields high external validity if the organization concerned is representative of a broader group of environments. On the other hand, it further diminishes the control that the experimenter has (e.g., participants might communicate), thus decreasing internal validity.

In addressing a research question of interest, a combination of these experimental methods would offer a spectrum ranging from the high internal validity of controlled laboratory experiments (Walker \& Willer, 2007) to the high external validity of natural field experiments (Harrison \& List, 2004). Different results between the laboratory and field settings would indicate that there is an interaction between, on the one hand, the distinct contextual variables between the two settings, and on the other hand, the relationship between the independent and dependent variables under investigation. This could lead to follow-up laboratory experiments, where such contextual variables are systematically varied. For example, one could add the possibility of participants knowing each other (as in the field) to the laboratory. Subsequently, the "updated" laboratory results can be used to modify the theory.

\section{STATE OF THE ART: TRUST AND SOCIAL NETWORKS IN THE EMPLOYER-EMPLOYEE RELATIONSHIP}

In spite of a noticeable increase in the use of experiments by social scientists, labor market behavior has not been extensively studied in experimental research. The limited number of studies that have been done are primarily based on laboratory experiments, with participants typically being university students. ${ }^{3}$ Behavioral economists, in particular, have shown some interest (see Falk \& Fehr, 2003 for an overview). Most of this experimental research studies the employment relationship between an employer and an employee after the latter has been hired. As is stereotypical for economics, an important focus is on labor market efficiency, monetary incentives, wage formation, and economic surplus. Behavioral economists often look beyond

3. An often raised objection is that results identified in laboratory experiments with students may not be relevant outside the laboratory because these participants are not familiar with the task and environment. To test the validity of this objection many studies have replicated laboratory experiments with "professionals" in their natural environment. Camerer (2015) concludes that most of these replications confirm the original laboratory results. 
this, however, and investigate market "irregularities", the role of other forms of social exchange, and underlying mechanisms such as reciprocity, fairness, and inequity aversion.

The starting point in much of this literature is that employment relationships (i.e., contracts) are often necessarily incomplete, that is, they are characterized by moral hazard (i.e., the hazard of opportunistic behavior when employees' performance and skills are difficult to observe) (Williamson, 1981). When this is the case, an important line of experimental work initiated by Fehr, Kirchsteiger, and Riedl (1993) shows that elements of trust and trustworthiness, fairness, and reciprocity have a strong influence on the workings of the labor market. The relationship between an employer and an employee is based on mutual trust and reciprocity: Employers give a trusting signal by offering high wages and employees reciprocate by exerting high effort. This "gift exchange" yields high efficiency, and as a consequence it leads to ongoing long-term partnerships (Brown, Falk, \& Fehr, 2004). Such an outcome was already observed in an early and seminal experimental study in sociology by Kollock (1994). Although not directly related to the labor market, this study looks at the establishment of fixed trading partnerships under conditions of uncertainty about the quality of the good to be traded. Also, here the importance of trustworthiness in trading relations is emphasized. ${ }^{4}$

Moral hazard issues play a role even before an employee has an employment relationship with the employer. In the hiring phase, employers can try to minimize the uncertainties in their expected exchange with future employees. A prime example is offered by the abundant sociological research showing that social networks play a crucial role in hiring (Marsden \& Gorman, 2001). Mostly based on observational and survey data, the evidence shows that employers rely on the social networks of their incumbent employees (Fernandez, Castilla, \& Moore, 2000), as well as on employers' own networks with family, friends, and professional contacts (Gërxhani \& Koster, 2015). Such networks serve to uncover information about potential employees, especially for jobs with high moral hazard. Although very valuable in providing detailed information on when and how employers hire job candidates, this research has been challenged in terms of the effect of social networks being causal or spurious (Mouw, 2003). It could be the case that employers with certain characteristics are capable of both establishing large social networks and hiring suitable employees. If so, one could not conclude that having social networks causes "success" in hiring.

4. In general terms, Kollock's study fits within the social exchange literature (Emerson, 1981), which focuses on the effects of structures of exchange on behavioral and affective outcomes. Much of this literature assumes explicitly negotiated exchange structures/contracts, which renders trust among actors unnecessary (Cook, Emerson, Gillmore, \& Yamagishi, 1983). As argued above, however, employment relationships are often necessarily "unguaranteed" (i.e. moral hazard). 
Only very recently there has been an increase in the implementation of causal research designs to study the dynamics between social networks and employers' hiring behavior. ${ }^{5}$ By combining a factorial survey (a.k.a. vignette) with an experimental design on a sample of English employers, Di Stasio and Gërxhani (2015) show that employers' business and professional networks are particularly valuable to them as a way to compensate for poor signaling by the education system. Kim and Fernandez (2017) also use a survey vignette experiment and examine whether the strength of social ties is a causal driver of networks' information benefits. Based on answers obtained from MBA students in the United States, they find that "potential referrers are more likely to relay job information to their friends than to acquaintances" (p. 268).

Such studies have undoubtedly contributed to a better understanding of the causal relationship between employers' social networks and hiring outcomes. Although more research is needed, one can cautiously say that the effect of social networks on hiring seems to be causal and not spurious. Nevertheless, it should be emphasized that although vignette (or audit and correspondence) studies are closer to the field than laboratory experiments are (because they try to mimic an actual hiring scenario and typically address actual employers) they do not create but simulate a hiring process. The conditions under which employers are asked to make hiring decisions are hypothetical and it remains an empirical question whether the same decisions would be made in a scenario where the decisions have real consequences.

A few recent laboratory experimental studies on social networks and hiring offer complementary insights not only regarding the causal effects of networks but also into the underlying mechanisms of such effects, and importantly on the emergence of employers' social networks. Schram, Brandts, and Gërxhani (2010) use a laboratory experiment where participants are incentivized to exchange a good (i.e., labor) in the role of a buyer (i.e., employer) or a seller (i.e., employee). Employers can obtain information from a (simulated) social network about an employee's trustworthiness in previous jobs. The authors then investigate how the possibility of receiving this information affects employers' decisions on which hiring channel to employ: a centralized market institution (such as an employment agency) or bilateral negotiations made possible via social network information. Results show that contrary to the economic intuition that market institutions always represent the efficient choice the information provided about a candidate's trustworthiness strongly affects the channels through which

5. There is rich literature in sociology that studies discrimination in hiring by using a type of "field experiment", known as audit and correspondence studies. For an overview of such designs, see Pager (2007). Similar methods have also been applied to study employers' consideration of candidates' educational credentials (Jackson, 2009). 
employers recruit, allowing them to hire more trustworthy employees and obtain higher efficiency via the social network. In a follow-up study, Brandts, Gërxhani, Schram, and Ygosse-Battisti (2010) examine the role of labor market size (in terms of the number of employers and employees) and observe that increasing this size by a factor of three does not affect these results.

In the previous two studies, information was exogenously provided to all employers by the experimenter. A subsequent question of whether employers are willing to share such beneficial information motivated a new laboratory study (Gërxhani, Brandts, \& Schram, 2013). Specifically, this addresses the question of "how and under what circumstances social networks amongst employers emerge that facilitate the dissemination of information about a job candidate's trustworthiness" (p. 541). Employers are given the opportunity to share information about prospective employees before making a wage offer. The essay concludes that mechanisms of conditional cooperation, reputation building, and direct reciprocity lead to the emergence of information networks among employers (even when it is costly to share information), which in turn increases employers' use of networks as a hiring channel. Doing so also affects the employer-employee exchange, as both parties benefit in terms of higher wages and higher revenues. Application of the experimental method enabled such detailed insights. By controlled variation of the variables that might affect employers' choice to resort to their social networks for information, the researcher is able to relate observed use of this information to these variables, thus isolating the underlying motivations for involving one's network. Needless to say, this is not possible with observational data.

A proper understanding of the hiring process requires studying both the emergence of social networks where employers exchange information and the effect of this information on the exchange between employers and employees. The studies discussed above highlight the important role that controlled experiments can play in this endeavor.

Finally, combining the laboratory results on labor market behavior in the pre- and post-hiring phases provides a rich overview. Before hiring, in order to decrease the uncertainty related to not knowing the trustworthiness of a prospective employee, employers establish information networks to obtain such information. They then use this information to reciprocate to the employee's past performance in previous jobs. Once a good match has been made, the employer-employee relationship continues based on mutual direct reciprocation where employees respond to high wages with high performance and vice versa. 


\section{MOVING FORWARD: ADVANCING THE MICROFOUNDATIONS OF LABOR MARKET BEHAVIOR}

More cutting-edge research on the microfoundations of labor market behavior is necessary. Experimentation in the laboratory or field is an emerging trend and can potentially lead to a much needed expansion of our knowledge on such microfoundations. But, this is just the beginning. Let me highlight here a few promising lines of research that tackle methodological challenges and offer opportunities for major new developments.

\section{Combining Experimental Methods}

Combining different research methods allows the researcher to benefit from their distinct advantages and compensate for the disadvantages. For example, laboratory experiments can be combined with framed field experiments, where the (same) design is implemented within organizations, and natural field experiments, where members of an organization face experimental treatment variation in their daily routines. Similarly, combining audit (correspondence) studies or survey vignettes with laboratory experiments could also offer new and promising insights. There are very few successful studies of such combinations. One is that of Correll, Benard, and Paik (2007), who combine a laboratory experiment with an audit study of actual employers to examine "motherhood" discrimination in hiring.

Both examples show that a combination of (quasi)-experimental methods allows for a better balance between the internal validity of a controlled environment and the external validity of a field setting. The external validity can be further strengthened by repetition of the field experiments, either across field settings (creating a cross section of controlled field observations) or over time (creating a longitudinal dataset). Repetition over time is particularly interesting because workplaces are characterized by dynamic processes of ongoing interactions and power relations. As a consequence, labor market rules, individual beliefs, and social norms may evolve in ways that limit the external validity of any single snapshot of their interaction.

\section{Cross-Country Experimental Comparisons}

Bills et al. (2017, p. 300) conclude that "A full specification of [ ... ] contextual conditions is still needed. In particular, more comparative research across different institutional and organizational contexts, where the focus is not only on formal institutions (i.e., rules and regulations) but also on informal institutions (i.e., social norms) would help clarify how employers contribute to the job match." Typically, comparative studies are based on observational 
field data. Because many aspects differ between any two countries, it is often difficult with such data to attribute a difference in the subject of interest to any specific difference between the countries. Longitudinal field data provide a step forward, but many differences persist over time (van der Lippe, de Ruijter, de Ruijter, \& Raub, 2011). Cross-country experimental studies (Gërxhani \& Schram, 2006; Heinrich et al., 2001) complement such field studies. They use experimental control over the environment to correct for between-country differences on external constraints, which allows the researcher to isolate causal relations under truly ceteris paribus conditions (Falk \& Heckman, 2009). I know of no existing study that compares employer hiring behavior in a controlled laboratory experiment implemented in multiple countries. Because the laboratory hiring regulations can be held constant across countries, such a study would allow for an investigation of the role of cross-country (e.g., cultural) differences that affect employers' choices above and beyond these institutional regulations.

\section{Investigating Online Networks and Labor Markets}

The ecology of organizational decision-making is changing, with social media and online networking becoming increasingly influential in external hiring. More research is needed in quantifying and understanding the role of online networks such as LinkedIn or Facebook in employers' hiring decisions. Are the underlying mechanisms of their workings comparable to or different from the more traditional type of networks that have dominated the literature? To a large extent, online networks resemble features of the laboratory experiments described above. They provide easily accessible platforms to share information about job candidates; it is costly to provide such information as one needs to find it; and the information can be provided discriminately. It would be an important line of research to examine whether, when, and how information-sharing networks emerge in such field environments and what their consequences are.

Moreover, the emergence of online labor markets such as Amazon Mechanical Turk (MTurk) and research tools such as Qualtrics has opened up new opportunities to conduct controlled experiments on labor market behavior with increased internal and external validity. Both offer access to a larger and more diverse pool of potential participants. In addition, MTurk enables the researcher to hire individuals outside the laboratory to do tasks designed to collect data under controlled variation (see Rand, 2012 for an overview). Studying hiring behavior with these new tools is another promising avenue for future research, as existing experiments can be replicated and new designs can be implemented. 
Reaching Toward Biological Explanations

A final promising line of research is an exploration of the interaction between social and biological processes in examining employers' decision-making. Recent works of Willer, Rogalin, Conlon, and Wojnowicz, (2013, p. 1016) emphasize that "social factors shape biological processes in important ways," which in turn have a strong influence on behavior. For example, employers' interactions in a social network might affect their levels of testosterone and cortisol. As a consequence, these hormones might affect the extent to which an employer is willing to share information on a candidate's trustworthiness. In an ongoing research (De Dreu, Gërxhani, \& Schram, 2017), we observe that a variation of the social context in which an individual performs a cognitive task yields differential biological responses and that these responses affect performance on the task. In a similar vein, a better grip on the biological underpinnings of the role of social networks in employers' behavior could provide important steps ahead in understanding this behavior.

\section{CONCLUSION}

Experiments provide a useful method for understanding many phenomena of interest in the social sciences. It is important to realize that experiments are complementary to other tools available to the researcher. A tool might present itself as particularly useful for some research questions while it provides little additional knowledge for others. And, sometimes, the best way to move forward is to use a combination of methods.

At the same time, some phenomena are notoriously more difficult than others to study. I have argued that employers' hiring behavior is a prime example. The main message of this essay is that the use of diverse experimental methods to address this is an emerging trend that takes us closer to an understanding of employer behavior by establishing causal relationships and specifying their underlying mechanisms. Moreover, recent technological developments, such as online labor markets, introduce new platforms where laboratory control can be exerted in environments that closely mirror the environment social scientists are interested in.

Another important contribution of experimentation is that it sheds light on the mechanisms generating labor market inequality. Existing experimental studies on employers' hiring indicate that their reliance on social networks can lead to social inequality on both the demand and supply sides. Because access to social networks is not equally distributed across employers, they have differential access to information, which leads to unequal chances in finding trustworthy employees. At the supply side, the more employers hire 
through their social networks, the more inequality there will be in who gets the jobs.

Although much can be studied using experiments, conventions about what can or cannot be done should be continuously challenged. For this, an interdisciplinary exchange of knowledge is essential. As shown in this essay, the existing knowledge on experimental labor market behavior benefits from interdisciplinary research bridging economics and sociology. There is a pressing need to maintain this trend by strengthening this bridge.

\section{REFERENCES}

Bills, D. B., Di Stasio, V., \& Gërxhani, K. (2017). The demand side of hiring: Employers in the labor market. Annual Review of Sociology, 43, 291-310.

Brandts, J., Gërxhani, K., Schram, A., \& Ygosse-Battisti, A. (2010). Size doesn't matter! Gift exchange in experimental labor markets. Journal of Economic Behavior and Organization, 76, 544-548.

Brown, M., Falk, A., \& Fehr, E. (2004). Relational contracts and the nature of market interactions. Econometrica, 72(3), 747-780.

Camerer, C. F. (2015). The promise and success of lab-field generalizability in experimental economics: A critical reply to Levitt and List. In G. R. Fréchette \& A. Schotter (Eds.), Handbook of experimental economic methodology (pp. 249-296). Oxford, England: Oxford University Press.

Cook, K. S., Emerson, R. M., Gillmore, M. R., \& Yamagishi, T. (1983). The distribution of power in exchange networks: Theory and experimental results. American Journal of Sociology, 89, 275-305.

Correll, S. J., Benard, S., \& Paik, I. (2007). Getting a job: Is there a motherhood penalty? American Journal of Sociology, 112, 1297-1338.

De Dreu, C., Gërxhani, K., \& Schram, A. (2017). Anticipating Performance Ranking Increases Cognitive Performance through Changes in Neurohormonal. Working paper.

Di Stasio, V., \& Gërxhani, K. (2015). Employers' social contacts and their hiring behavior in a factorial survey. Social Science Research, 51, 93-107.

Emerson, R. M. (1981). Social exchange theory. In M. Rosenberg \& R. Turner (Eds.), Social psychology: Sociological perspectives (pp. 30-65). New York, NY: Basic Books.

Falk, A., \& Fehr, E. (2003). Why labour market experiments? Labour Economics, 10, 399-406.

Falk, A., \& Heckman, J. (2009). Lab experiments are a major source of knowledge in the social sciences. Science, 326, 535-538.

Fehr, E., Kirchsteiger, G., \& Riedl, A. (1993). Does fairness prevent market clearing? An experimental investigation. Quarterly Journal of Economics, 108(2), 437-460.

Fernandez, R. M., Castilla, E. J., \& Moore, P. (2000). Social capital at work: Networks and employment at a phone center. American Journal of Sociology, 105(5), 1288-1356.

Gërxhani, K., Brandts, J., \& Schram, A. (2013). The emergence of employer information networks in an experimental labor market. Social Networks, 35, 541-560. 
Gërxhani, K., \& Koster, F. (2015). Making the right move: Investigating employers' recruitment strategies. Personnel Review, 44(5), 781-800.

Gërxhani, K., \& Schram, A. (2006). Tax evasion and income source. Journal of Economic Psychology, 27, 402-422.

Granovetter, M. S. (1974). Getting a job: A study of contacts and careers. Cambridge, MA: Basic Books.

Harrison, G. W., \& List, J. A. (2004). Field experiments. Journal of Economic Literature, 42(4), 1009-1055.

Heinrich, J., Boyd, R., Bowles, S., Camerer, C., Fehr, E., Gintis, H., \& McElreath, R. (2001). In search of homo economicus: Behavioral experiments in 15 small-scale societies. American Economic Review, 91, 73-78.

Hertwig, R., \& Ortmann, A. (2001). Money, lies, and replicability: On the need for empirically grounded experimental practices and interdisciplinary discourse. Behavioral and Brain Sciences, 24, 433-444.

Jackson, M. (2009). Disadvantaged through discrimination. The role of employers in social stratification. British Journal of Sociology, 60(4), 669-692.

Jackson, M., \& Cox, D. R. (2013). The principles of experimental design and their application to sociology. Annual Review of Sociology, 39, 27-49.

Kim, M., \& Fernandez, R. M. (2017). Strength matters: Tie strength as a causal driver of networks' information benefits. Social Science Research, 65, 268-281.

Kollock, P. (1994). The emergence of exchange structures: An experimental study of uncertainty, commitment, and trust. American Journal of Sociology, 100(2), 313-345.

Marsden, P., \& Gorman, E. (2001). Social networks, job changes, and recruitment. In I. Berg \& A. L. Kalleberg (Eds.), Sourcebook of labor markets: Evolving structures and processes (pp. 467-502). New York, NY: Kluwer Academic/Plenum Publishers.

Mouw, T. (2003). Social capital and finding a job: Do contacts matter? American Sociological Review, 68(6), 868-898.

Pager, D. (2007). The use of field experiments for studies of employment discrimination: Contributions, critiques, and directions for the future. Annals of the American Academy of Political and Social Science, 609(1), 104-133.

Przepiorka, W., \& Diekmann, A. (2013). Temporal embeddedness and signals of trustworthiness. European Sociological Review, 29(5), 1010-1023.

Rand, D. G. (2012). The promise of mechanical Turk: How online labor markets can help theorists run behavioral experiments. Journal of Theoretical Biology, 299, 172-179.

Schram, A. (2005). Artificiality: The tension between internal and external validity in economic experiments. Journal of Economic Methodology, 12(2), 225-238.

Schram, A., Brandts, J., \& Gërxhani, K. (2010). Information, bilateral negotiations, and worker recruitment. European Economic Review, 54, 1035-1058.

van der Lippe, T., de Ruijter, J., de Ruijter, E., \& Raub, W. (2011). Persistent inequalities in time use between men and women. European Sociological Review, 27(2), 164-179.

Walker, H. A., \& Willer, D. (2007). Experiments and the science of sociology. In M. Webster Jr., \& J. Sell (Eds.), Laboratory experiments in the social sciences (pp. 25-54). Amsterdam, The Netherlands: Elsevier. 
Willer, R., Rogalin, C. L., Conlon, B., \& Wojnowicz, M. T. (2013). Overdoing gender: A test of the masculine overcompensation thesis. American Journal of Sociology, 118(4), 980-1022.

Williamson, O. E. (1981). The economics of organization: The transaction cost approach. American Journal of Sociology, 87(3), 548-577.

\section{KLARITA GËRXHANI SHORT BIOGRAPHY}

Klarita Gërxhani is Professor of Economic Sociology at the European University Institute in Florence, Italy. She received her PhD in Economics at the Tinbergen Institute and the Faculty of Economics and Business at the University of Amsterdam. Her main expertise lies in the microfoundations of economic sociology. She has published on a variety of topics, including employers' hiring behavior, social norms, social status and gender (in)equalities, social capital, informal economies, and tax evasion. Her research is best characterized as interdisciplinary. It combines laboratory and field experiments with field surveys and economic sociological theory. She is the author of various articles published in internationally peer-reviewed journals, including the Annual Review of Sociology, Social Networks, PloS ONE, European Sociological Review, European Economic Review, Social Science Research, Journal of Economic Psychology, European Journal of Political Economy, and Journal of Economic Behavior \& Organization. She has received two major research grants from the Netherlands' Organization for Scientific Research (NWO).

\section{RELATED ESSAYS}

Returns to Education in Different Labor Market Contexts (Sociology), Klaus Schöemann and Rolf Becker

Rent, Rent-Seeking, and Social Inequality (Sociology), Beth Red Bird and David B. Grusky

To Flop Is Human: Inventing Better Scientific Approaches to Anticipating Failure (Methods), Robert Boruch and Alan Ruby

Misinformation and How to Correct It (Psychology), John Cook et al.

The Reorganization of Work (Sociology), Charles Heckscher

Network Research Experiments (Methods), Allen L. Linton and Betsy Sinclair Transformation of the Employment Relationship (Sociology), Arne L. Kalleberg and Peter V. Marsden

Implicit Attitude Measures (Psychology), Gregory Mitchell and Philip E. Tetlock

Knowledge Transfer (Psychology), Timothy J. Nokes-Malach and J. Elizabeth Richey

Quasi-Experiments (Methods), Charles S. Reichardt 
The Rise of Experimentation in Political Science (Political Science), Ronald Rogowski

Virtual Worlds as Laboratories (Methods), Travis L. Ross et al.

How Do Labor Market Networks Work? (Sociology), Brian Rubineau and Roberto M. Fernandez

Impact of Limited Education on Employment Prospects in Advanced Economies (Sociology), Heike Solga

How Brief Social-Psychological Interventions Can Cause Enduring Effects (Sociology), Dushiyanthini (Toni) Kenthirarajah and Gregory M. Walton

Gender and Work (Sociology), Christine L. Williams and Megan Tobias Neely 